inert core leads to a source of neutrons (through the reaction ${ }^{13} \mathrm{C}\left({ }^{4} \mathrm{He}, \mathrm{n}\right){ }^{16} \mathrm{O}$ in which ${ }^{13} \mathrm{C}$ fuses with a helium nucleus, releases a neutron and transmutes into ${ }^{16} \mathrm{O}$ ), so allowing the s-process nucleosynthesis to take place.

One of the prime questions is whether a single star was involved or whether several stars contributed to give the wide range of isotope compositions. In models of thermally pulsing AGB stars, variations in carbon isotopes are readily explained, as consecutive episodes of hydrogen and helium burning result in, respectively, enrichments of ${ }^{13} \mathrm{C}$ and ${ }^{12} \mathrm{C}$. As the components of these different events are mixed together, a variety of carbon isotope ratios can be produced. Thus, a single star can produce the range of carbon isotope compositions seen in the $\mathrm{SiC}$ grains. The relationship of silicon isotopes has also been explained in terms of evolution of a single star original ${ }^{28} \mathrm{Si}$-rich material is considered to become enriched in ${ }^{29} \mathrm{Si}$ and ${ }^{30} \mathrm{Si}$ as a result of neutron capture during the helium-burning phase ${ }^{6}$. But the observed relationship of ${ }^{29} \mathrm{Si} /{ }^{28} \mathrm{Si}$ and ${ }^{30} \mathrm{Si} /{ }^{28} \mathrm{Si}$ does not match that predicted from theoretical modelling of AGB stars.

New work reported by D. D. Clayton and L. E. Brown (Clemson University) shows that the silicon isotope composition in an AGB star can be radically affected by the neutron-capture reaction ${ }^{33} \mathrm{~S}\left(\mathrm{n},{ }^{4} \mathrm{He}\right){ }^{30} \mathrm{Si}$. At the same time, ${ }^{22} \mathrm{Ne}$ is turned into ${ }^{25} \mathrm{Mg}$ and ${ }^{26} \mathrm{Mg}$ by the helium-burning reactions ${ }^{22} \mathrm{Ne}\left({ }^{4} \mathrm{He}, \mathrm{n}\right){ }^{25} \mathrm{Mg}$ and ${ }^{22} \mathrm{Ne}\left({ }^{4} \mathrm{He}, \gamma\right){ }^{26} \mathrm{Mg}$, where $\gamma$ is a radiated $\gamma$-ray photon. When the neon is exhausted, the magnesium begins to burn thereby producing the lighter silicon isotopes. Eventually ${ }^{25} \mathrm{Mg}$ becomes exhausted, and the silicon isotope ratios begin to evolve to produce something like that seen in the $\mathrm{SiC}$ grains.

The model is flawed, as the effect on the silicon isotope ratios is 100 -times that actually seen. What has to be inferred, if the model is correct, is that the isotopically enriched silicon, produced from helium burning, is mixed with normal silicon in the star's envelope and thus diluted. A consequence of this new model is that magnesium isotope ratios change quite drastically - incomplete magnesium burning may give rise to excesses in ${ }^{26} \mathrm{Mg}$, which could subsequently be misinterpreted as the decay product of ${ }^{26} \mathrm{Al}$.

The s-process isotope signatures observed previously in $\mathrm{SiC}$ have in some cases been obtained by making measurements on collections of grains (there simply not being enough atoms of the appropriate nuclides in individual crystals). The noble gases xenon and krypton, which provided the first unequivocal evidence that certain components in meteorites were formed through s- process nucleosynthesis, are measured in this way; isotopic measurements of neon have also been obtained by lumping together large numbers of grains. In a new study, R. H. Nichols (Washington University) and colleagues have used a laser probe to liberate helium and neon from individual $\mathrm{SiC}$ grains (analysed previously for their $\mathrm{Si}$ and $\mathrm{C}$ isotopic compositions). This work shows that only 4 per cent of all $\mathrm{SiC}$ grains contain ${ }^{22} \mathrm{Ne}$ and ${ }^{4} \mathrm{He}-$ the rest are gas-poor. The ${ }^{4} \mathrm{He}$ and ${ }^{22} \mathrm{Ne}$ are characteristic of processing in an AGB star. What is of interest here is the observation that most grains appear to contain no trapped gases. If these were degassed at the time when the solar nebula spawned primitive meteorite parent bodies, then previous estimates of the ages of the grains (which are assessed by making measurements of neon isotopic compositions) could be erroneously low. As such, the ages of $\mathrm{SiC}$ could be more commensurate with theoretical estimates which suggest that the grains should be 400 million years older than the Solar System ${ }^{7}$.

A search continues for $\mathrm{SiC}$ grains which do not conform to the normal relationship in ${ }^{29} \mathrm{Si} /{ }^{28} \mathrm{Si}$ and ${ }^{30} \mathrm{Si} /{ }^{28} \mathrm{Si}$. Two such populations have now been observed, which S. Amari (Washington University) and colleagues have christened grains $\mathrm{x}$ and grains $\mathrm{y}$. The latter population is only subtly different in isotopic composition from normal grains and their interpretation is not clear.

Grains $x$, on the other hand, show large enrichments in ${ }^{12} \mathrm{C},{ }^{15} \mathrm{~N},{ }^{26} \mathrm{Al}$ and ${ }^{28} \mathrm{Si}$. There are also excesses in ${ }^{44} \mathrm{Ca}$ and ${ }^{49} \mathrm{Ti}$, thought to be the decay products of ${ }^{44} \mathrm{Ti}$ and ${ }^{49} \mathrm{~V}$ respectively, which suggests they originated in a supernova. However, the apparent enrichment in ${ }^{26} \mathrm{Al}$ is not consistent with this picture; clearly the origin of these grains is not yet fully understood.

Thus the question remains: how many sources for the $\mathrm{SiC}$ ? On the basis of the evidence we have thus far, it looks like only a limited number of discrete sites are necessary to explain the data. Undoubtedly as more $\mathrm{SiC}$ grains are analysed the story will become more complex and, indeed, more fascinating.

1. P. Wright is in the Department of Earth Sciences, The Open University, Walton Hall, Milton Keynes MK7 6AA, UK.

1. Zinner, E., Tang, M. \& Anders, E. Nature 330, 730-732 (1987)

2. Tang. M., Anders, E., Hoppe, P. \& Zinner, E. Nature 339 351-354 (1989)

3. Lewis, T. S., Amari, S. \& Anders, E. Nature $\mathbf{3 4 8}$, 293-298 (1990)

. Zinner, E., Amari, S., Anders, E. \& Lewis, R. S. Nature 349, 51-54 (1991)

5. Gallino, R., Busso, M., Picchio, G. \& Raiteri, C. M Nature 348, 298-302 (1990).

6. Stone, J., Hutcheon, I. D., Epstein, S. \& Wasserburg, G. J. Earth planet. Sci. Lett. 107, 570-581 (1991) 7. McKee, C. IAU Symp. 135, 431-433 (1989).

\section{A drug in a bug}

DRUG-addiction creates an enormous amount of crime, misery, and social disruption. All of it could be avoided if addictive drugs were freely available. Once legalized, however, they would be rapidly spread by advertising and commercial enterprise, giving rise to new social problems. Daedalus now resolves the dilemma. He proposes a drug that you don't have to buy, and cannot sell.

His scheme exploits that miserable medical phenomenon, the permanent abscess or 'septic focus'. Before antibiotics, many people went for years with such chronic bacterial infections, typically in the inner ear or beneath a tooth root. So DREADCO biologists are creating a novel drug-bacterium. They are extracting the genes for cocaine synthesis from the coca-plant and genetically engineering them into Staphylococcus. An addict who is sick of the endless struggle to obtain an illegal drug, can simply apply to be stably infected with this drug-synthesizing organism.

Once the benevolent stable infection is leaking cocaine steadily into his bloodstream, the addict's troubles will be over. He will no longer be tempted into crime, or indeed any other activity. With his pleasure centres permanently satiated by internally generated drug, he will be absolved from the goal-seeking, troubleavoiding pressures that beset the rest of us. He will decline the increasingly desperate offers of his distraught pusher with a pitying smile.

Intrinsically content, immune to threats, pleas and demands of any kind, 'auto-addicts' will be the most unworldly, even saintly, beings imaginable. They will still be a drain on the welfare services, but not seriously, and probably not for long. Their indifference to food and basic hygiene will steadily undermine their vitality. At any stage, of course, an auto-addict could seek medication with antibiotics, so as to return to the worried, driven life of the responsible citizen but few will bother. Meanwhile, the illegal drug business will simply collapse. Its heavy social burden of crime, propagation of AIDS and destruction of community, will be lifted.

At first Daedalus feared that his drugbugs might spread disruptively into respectable society at large. But he now points out that their useless burden of cocaine synthesis will handicap them strongly. They will be unable to compete with more efficient, naturally occurring bacteria. The only way you could get infected would be by the deliberate effort of having a strong culture injected beneath a tooth root, or other suitable site. It would be the last deliberate effort you would ever make.

David Jones 